\title{
Comparing Excess Costs Across Multiple Corporate Populations
}

\author{
Douglas Wright, PhD \\ Laura Adams, MBA \\ Marshall J. Beard, CEBS, CLU, ChFC \\ Wayne N. Burton, MD \\ David Hirschland, MBA \\ Timothy McDonald, MHS \\ Deborah Napier, MS, CHES \\ Salvatore Galante, MD, MPH \\ Thomas Smith

\section{W. Edington, PhD}

The purpose of this study was to examine the relationship of health risk level to charged medical costs and determine the excess cost of higher risk individuals compared to low risk. Two years of medical claims from six corporations were used to determine costs of health risk assessment (HRA) participants and nonparticipants. A total of 165,770 employees, 21,124 of which took an HRA, were used for the study. Costs increased as risk level increased. There were no significant differences within a risk level between companies for the cost ratio. Percent of medical costs due to excess risk ranged from 15.0-30.8\% for HRA participants and $23.8-38.3 \%$ for the study population. Cost patterns were consistent across companies. Excess cost as the result of increased risk level accounted for a substantial portion of the cost at each company. These results can be used to justify the need for a health-promotion program and to estimate potential savings as the result of excess risk. Even without the use of an HRA, health practitioners should feel confident stating that excess risk accounts for at least $25 \%$ to $30 \%$ of medical costs per year across a wide variety of companies, regardless of industry or demographics. The numbers can be used as a realistic estimate for any health promotion program financial proposal. (J Occup Environ Med. 2004;46:937-945)

From the Health Management Research Center, University of Michigan, Ann Arbor, Michigan (Drs Wright, Edington); The Progressive Corporation, Mayfield Village, Ohio (Ms Adams); Steelcase, Inc, Grand Rapids, Michigan (Mr Beard); Bank One, 1 Bank One Plaza, Chicago, Illinois (Dr Burton); International Union, United Automobile, Aerospace and Agricultural Implement Workers of America, Detroit, Michigan (Mr Hirschland); General Motors Corporation, Detroit, Michigan (Mr McDonald); Xerox Corporation, Webster, New York (Ms Napier); and Delphi Corporation, Troy, Michigan (Dr Galante, Mr Smith).

Address correspondence to: D.W. Edington, PhD, Health Management Research Center, University of Michigan, 1027 E. Huron St., Ann Arbor, MI 48104-1688. E-mail address: dwe@umich.edu or wrightdw@umich.edu.

Copyright $($ ) by American College of Occupational and Environmental Medicine

DOI: 10.1097/01.jom.0000137949.40596.ff istorically, national health expenditures have risen at a faster rate than inflation. ${ }^{1}$ National health expenditures in 1999 were more than 1.2 trillion dollars, which includes private expenditures of $\$ 662$ billion, of which $\$ 401$ billion was paid by private insurance. $^{2}$ Of this, $\$ 252$ billion was spent by private insurance to pay for hospital care and physicians' services. It has been shown that corporate health benefits are close to $60 \%$ of after-tax profit. ${ }^{3}$ Obviously, any percent decrease in these outlays would equal substantial cost savings to employers and/or employees.

The literature indicates that only a small segment of the population is responsible for the majority of health care expenditures. From $15 \%$ to $30 \%$ of the total annual medical cost has been attributed to the top $1 \%$ to $2 \%$ of the total population with the highest medical expenditures and $70 \%$ to $90 \%$ of the annual total cost has been attributed to the top $10 \%$ to $15 \%$ of the population, although it is not necessarily the same people each year. ${ }^{4-7}$ The association between health behavior and medical claims costs has been well established in the literature. ${ }^{8-12}$

Using a high-cost analysis technique, research conducted at Texas A\&M University demonstrated that more than $43 \%$ of the costs of medical claims were associated with elevated risk. ${ }^{13}$ A study of Procter \& Gamble employees showed similar results, where on average, potential lifestyle-related medical costs accounted for approximately $35 \%$ of their 3-year total medical costs. ${ }^{14}$ Their results were also consistent on 
a yearly basis with $34.8 \%, 33.8 \%$, and $37.7 \%$ of medical costs for years one, two, and three being attributed to higher risk levels.

Wasserman et al $^{15}$ showed the excess cost of individual risks compared to those with no risks in people with coronary heart disease. People who reported being depressed had health care expenditures $42.1 \%$ higher than those with no risks. Those with high glucose levels, high stress, smoke, obese, and physically inactive had costs $37.8 \%, 27.1 \%, 26.4 \%, 22.7 \%$, and $16.1 \%$, respectively, higher than those with no risks. They also noted distinct gender differences in the excess costs of different risk factors. For instance, depression, smoking, and high blood pressure were the most expensive for men whereas high blood glucose, high stress, and obesity were the most expensive for women compared with those with no risk factors.

The purpose of this study is to examine the relationship of health risk level (defined as low, medium, and high) to charged medical costs and to determine the excess cost of higher-risk individuals across multiple corporations. Excess cost among the general employee population, as well as that between those with and without major diseases, will be determined. Excess cost in this study is defined as the difference in medical care costs between the low-risk group and the other respective risk groups times the respective number of people in each group. ${ }^{16}$

\section{Methods}

This study examined the relationship between excess charged medical claims costs and level of health risk, as determined by a health risk assessment (HRA). Medical claims of HRA nonparticipants also were examined. HRA information, along with 2 years of medical claims data after and including the year the HRA was given were collected from six corporations. The corporations included four manufacturing companies, an insurance-hold- ing company, and a financial services company: General Motors Corporation; Delphi; Steelcase, Inc.; Xerox Corporation; The Progressive Corporation; and Bank One. All charged medical claims costs were from employees enrolled in traditional indemnity or PPO plans. Charged costs were used because of the widely varying medical plans at each company. Pregnancy costs were not removed, since some companies did not have that information available. All employees had to be actively employed by the company for the same length of time as the medical claims data, be younger than 65 years of age, and at least 19 years of age. Medical claims per individual were summed over the time period and divided by the number of years to give an average charged medical cost per year. Employees without medical claims but who were verified to be a member of the plan were assigned a zero medical cost. All medical claims were adjusted for the impact of inflation by converting them into year 2000 dollar equivalents using the Medical Care Consumer Price Index (Medical Care: All Items). ${ }^{17}$ Drug costs were not included in medical costs.

The HRA questionnaire used at each corporation was originally developed by the Centers for Disease Control/Carter Center and modified by the University of Michigan Health Management Research Center to meet the needs of each employer. In general, besides selfreported age and gender, 15 healthrelated factors measured on the HRA were selected to establish health status. ${ }^{9}$ A list of the risk factors and their associated high-risk criteria is shown in Table 1. The risks fall into three main categories: psychological, lifestyle/biological, and other. Psychological risks include stress, perception of physical health, life satisfaction, and job satisfaction. Lifestyle/biological risks include tobacco use, alcohol use, safety belt use, drug/medication use, physical activity level, illness absence days, blood pressure, cholesterol, body mass index, and serious medical problems. One additional risk included was health age index, where the appraised age minus the achievable age (from HRA algorithms) is greater than 4 years. There were some differences in company questionnaires limiting the availability of some variables.

Risk levels were defined as $0-2$ risks being low-risk, 3-4 risks being medium-risk, and 5 or greater risks being high-risk based on a maximum total of 13-15 risks depending on the specific HRA used by each corporation.

All statistical procedures were performed using SAS. ${ }^{18}$ Categorical variables were tested using the Pearson $\chi^{2}$ statistic. Charged medical costs were first analyzed using the general linear models (GLM) procedure in SAS with a model containing risk level. Each company was analyzed separately. A least-squares mean was calculated for low risk for each company. The average annual charged medical cost for each individual was then divided by their respective company low risk mean to create a ratio. This was necessary because of the wide variation in average medical costs between the companies. By dividing each individual by their respective low risk mean, it forced the low risk mean of each company to be 1.0.

The data from the individual companies were then combined and medical costs ratios were analyzed using the GLM procedure, adjusting for the main effects of company, risk level, and the interaction. Least-squares means of the interaction were computed and compared using the PDIFF option, with a Tukey-Kramer adjustment for multiple comparisons.

A secondary analysis was performed comparing HRA participants with and without self-reported major disease (cancer, diabetes, heart problems, past stroke, chronic bronchitis/ emphysema). HRA participants without disease were classified into low-, medium-, and high-risk groups using the previous criteria (with the 
TABLE 1

High Health Risk Criteria

Selected Measures

High Risk Criteria

\begin{tabular}{|c|c|}
\hline \multicolumn{2}{|l|}{ Lifestyle/Biological Risks } \\
\hline Smoking & Current cigarette smoker \\
\hline Physical activity & $<1$ time per week \\
\hline Alcohol use & Heavy drinker (>14 drinks/wk) \\
\hline Drug/medication use* & Sometimes or almost every day \\
\hline Safety belt use & Using safety belt less than $100 \%$ of the time \\
\hline Absent due to illness & Six days or more during last year \\
\hline Medical problems & Had problems with heart condition, cancer, diabetes, stroke or bronchitis/emphysema \\
\hline Blood pressure & $\begin{array}{l}\text { Systolic blood pressure greater than } 139 \mathrm{~mm} \mathrm{Hg} \text { or diastolic blood pressure greater than } \\
89 \mathrm{~mm} \mathrm{Hg} \text { or taking blood pressure medication or self reported high }\end{array}$ \\
\hline Cholesterol & Greater than $239 \mathrm{mg} / \mathrm{dL}$ \\
\hline Body Mass Index & Over $27.5 \mathrm{~kg} / \mathrm{m}^{2}$ \\
\hline \multicolumn{2}{|l|}{ Psychological Risks } \\
\hline Personal life satisfaction & Partly satisfied or not satisfied \\
\hline Job satisfaction & Satisfied with job? (disagree or disagree strongly) \\
\hline Stress & Stress-scale score over 18 \\
\hline Perception of health & Fair or poor \\
\hline \multicolumn{2}{|l|}{ Other Risk } \\
\hline Health Age Index & Appraised age minus achievable age (from HRA) $>4 \mathrm{yr}$ \\
\hline \multicolumn{2}{|l|}{ Overall risk levels } \\
\hline Low risk & $0-2$ risks \\
\hline Medium risk & $3-4$ risks \\
\hline High risk & 5 or more risks \\
\hline
\end{tabular}

*Use of medication and/or drugs (including prescription), which affect mood or help to relax.

exception of major disease). HRA participants with disease were treated as one group regardless of other risks. Using previous statistical methods, the low-risk group cost ratio was set to 1.0 within each company and then compared with the other risk groups and disease group, using the excess cost ratio.

The following is a brief description of each company and their respective health promotion programs. A more detailed description of each company has been described previously. ${ }^{19}$

\section{Progressive}

The Progressive Corporation is a Cleveland-based insurance-holding company with subsidiaries that offer insurance and related services throughout the United States. Their wellness program was initiated in $1987 .^{20}$ For this study, the HRA information from 1999 was used along with the medical claims data from 1999-2000.

\section{General Motors}

General Motors Corporation is a multinational company mainly in- volved in the manufacture of automobiles and related activities. General Motors Corporation initiated their LifeSteps health promotion program in 1996. The core program of LifeSteps is a health education, awareness, and communications program offered nationwide to employees, retirees, spouses, and dependents. ${ }^{21}$ For this study the HRA information from 1999 was used along with the medical claims data from 1999 to 2000. The HRA used for GM counts a maximum of 13 risks, excluding job satisfaction and drug/medication use to relax.

\section{Delphi}

Delphi is a multinational company involved in the manufacture of parts for the automobile industry. Prior to becoming an independent company in 1999, Delphi was part of General Motors Corporation and used their LifeSteps health promotion program. Their current program is a slight modification of the LifeSteps program. For this study the HRA information from 1999 was used along with the medical claims data from
1999-2000. The HRA used for Delphi also counts a maximum of 13 risks, excluding job satisfaction and drug/medication use to relax.

\section{Xerox}

The Xerox Corporation is a manufacturer of office equipment such as copiers and printers. The Xerox Corporation initiated the Xerox Health Management program in $1978 .{ }^{22} \mathrm{Xe}-$ rox provides a full spectrum of health programs and services ranging from general awareness materials and self-directed behavior change programs to on-demand and interactive web-based programs. For this study the HRA information from 1995 was used along with the medical claims data from 1995-1996.

\section{Steelcase}

Steelcase, Inc. is a manufacturer of office equipment and furniture based in Grand Rapids, Michigan. Steelcase initiated its Wellness program in 1982 with the first wave of HRAs offered with biometric screening in 1985 . During the early years, HRA screenings were of- 
fered on a 3-year rotation using 3 years to complete screenings within all departments and later moved to a 2 -year rotation. ${ }^{23}$ Since 1998, HRA screenings are offered on an annual basis. For this study the HRA information from 1999 was used along with the medical claims data from 1999-2000.

\section{Bank One}

Bank One was formed by the merger of First Chicago NBD and Banc One in 1998 and is the holding company for the nation's fifth largest bank, First USA credit cards, and other financial subsidiaries. ${ }^{24}$ The First Chicago NBD corporate wellness program was established in 1982. For this study, the HRA information from 2000 was used along with the medical claims data form 2000-2001. The HRA used for Bank One counts a maximum of 14 risks, excluding illness absence days.

\section{Results}

An overview of the six corporations is shown in Table 2. The six employers differed in geographical location, size, and type. Demographic characteristics of the six companies are shown in Table 3 . There were significant differences between the companies for gender, age categories, and HRA participation $(P<0.001)$. The average age (at time of HRA) of employees in each company was significantly different $(P<0.001)$ from each other, except for UAW-GM and Xerox, ranging from a low of 34.4 years at Progressive to a high of 48.6 years at UAW-GM and Xerox.
The incidence of risks is shown in Table 4. There were significant differences between the companies for each risk $(P<0.005)$. The overall risk level (low, medium, high) was significantly different between the companies $(P<0.05)$, even though there was only a four-percentage point difference in low risk between the highest and lowest company.

Despite the differences in company classifications, demographics, and risks, the results were relatively consistent across the six companies. As risk level increased, so did the resulting medical claims cost for HRA participants (Table 5). Excess costs of medium and high-risk groups increased linearly compared with low risk, with the exception of Bank One, where the costs of medium-risk employees were higher than the high-risk employees. The medical costs of HRA nonparticipants fell either in between low and medium or in between medium- and high-risk excess cost depending on the company. The medium-risk cost ratio ranged from a low of 1.13 at Steelcase to a high of 1.73 at Delphi; however, the differences were not significant. The high-risk cost ratio ranged from a low of 1.58 at Bank One to a high of 2.70 at Xerox and the six companies were not significantly different from each other. The percent excess cost of medium and high-risk HRA participants compared with low- risk participants ranged from $15.0 \%$ at Steelcase to $30.8 \%$ at Delphi.

The excess cost ratio for HRA nonparticipants ranged from 1.29 at
Xerox to 1.66 at Steelcase. The Steelcase and Delphi nonparticipant cost ratio was significantly $(P<$ 0.01 ) different from all the other nonparticipant groups except for Steelcase compared with Xerox, and Steelcase compared with Bank One $(P<0.05)$. The percent excess cost of the study population (medium-, high-risk, and nonparticipants) compared with low-risk participants ranged from $23.8 \%$ at Progressive to $38.3 \%$ at Delphi.

HRA participants with self-reported major diseases were on average 3.9 years older than those without disease, ranging from a difference of 3.2 years at Progressive to 4.7 years at Bank One (data not shown). Gender ratios, within a company, between those with and without disease were similar. There were significant differences between the companies for gender and age categories $(P<0.001)$. The average age of employees in each company was significantly different $(P<0.001)$ from each other, except for UAW-GM and Xerox, and Bank One and Steelcase. Average age ranged from a low of 38.2 years at Progressive to a high of 52.6 years at UAWGM.

Excess cost ratios for HRA participants with and without self-reported major diseases are shown in Table 6. Excess costs of medium- and highrisk groups without disease increased linearly compared with low risk, with the exception of Bank One, where the costs of medium-risk employees were higher than the highrisk employees. The medical costs of HRA participants with self-reported

\section{TABLE 2}

Corporation Overviews

\begin{tabular}{lllllll} 
& Bank One & UAW-Delphi & UAW-GM & Progressive & Steelcase & Xerox \\
\hline Company type & Banking & Manufacturing & Manufacturing & Insurance & Manufacturing & Manufacturing \\
Location & Nationwide & Nationwide & Nationwide & Nationwide & Midwestern city & Northeastern city \\
Number of employees* & 6035 & 30,525 & 111,473 & 8650 & 5235 & 3852 \\
Year(s) of HRA & 2000 & 1999 & 1999 & 1999 & 1999 & 1995 \\
Medical cost time period & $2000-2001$ & $1999-2000$ & $1999-2000$ & $1999-2000$ & $1999-2000$ & $1995-1996$ \\
\hline
\end{tabular}

${ }^{\star}$ Employed during the total length of the respective analyses. 
TABLE 3

Demographic Characteristics of Corporate Populations

\begin{tabular}{|c|c|c|c|c|c|c|}
\hline Demographics & Bank One & UAW-Delphi & UAW-GM & Progressive & Steelcase & Xerox \\
\hline \multicolumn{7}{|l|}{ Gender* } \\
\hline Male $(n=127957)$ & $2170(36.0 \%)$ & 22458 (73.6\%) & 92203 (82.3\%) & $3893(45.0 \%)$ & 4216 (80.5\%) & 3017 (78.3\% \\
\hline Female $(n=37813)$ & 3865 (64.0\%) & 8067 (26.4\%) & $19270(17.3 \%)$ & 4757 (55.0\%) & 1019 (19.5\%) & $835(21.7 \%$ \\
\hline \multicolumn{7}{|l|}{ Age, $\mathrm{yr}^{\star \dagger}$} \\
\hline $19-34(n=14029)$ & 1919 (31.8\%) & $1579(5.2 \%)$ & $4541(4.1 \%)$ & 4968 (57.4\%) & $913(17.4 \%)$ & $109(2.8 \%)$ \\
\hline $35-44(n=42222)$ & 1795 (29.7\%) & 7409 (24.3\%) & $27369(24.6 \%)$ & $2536(29.3 \%)$ & 2167 (41.4\%) & $946(24.6 \%$ \\
\hline $45-54(n=76663)$ & 1665 (27.6\%) & 16381 (53.7\%) & $54002(48.4 \%)$ & 908 (10.5\%) & 1729 (33.0\%) & 1978 (51.4\% \\
\hline $55-64(n=32856)$ & $656(10.9 \%)$ & 5156 (16.9\%) & $25561(22.9 \%)$ & $238(2.8 \%)$ & $426(8.1 \%)$ & $819(21.3 \%$ \\
\hline Average Age, $\mathrm{yr}^{\dagger}$ & $40.4^{a}$ & $47.7^{\mathrm{b}}$ & $48.6^{c}$ & $34.4^{d}$ & $42.5^{\mathrm{e}}$ & $48.6^{c}$ \\
\hline \multicolumn{7}{|l|}{ HRA Participant* } \\
\hline Yes $(n=21124)$ & $1308(21.7 \%)$ & $4479(14.7 \%)$ & $11246(10.1 \%)$ & $1964(22.7 \%)$ & $1071(20.5 \%)$ & $1056(27.4 \%$ \\
\hline No $(n=144646)$ & 4727 (78.3\%) & $26046(85.3 \%)$ & 100227 (89.9\%) & $6686(77.3 \%)$ & $4164(79.5 \%)$ & 2796 (72.6\% \\
\hline
\end{tabular}

${ }^{\star} P<0.001, \chi^{2}$

${ }^{\dagger}$ Age at time of HRA.

$\mathrm{a}, \mathrm{b}, \mathrm{c}, \mathrm{d}, \mathrm{e}$ Means in a row with differing letters are statistically significant at $P<0.001$, GLM with Tukey-Kramer adjustment for multiple comparisons.

\section{TABLE 4}

Risk Incidence* of Corporate Populations

\begin{tabular}{|c|c|c|c|c|c|c|}
\hline Health Risk & Bank One & UAW-Delphi & UAW-GM & Progressive & Steelcase & Xerox \\
\hline Smoking** & $10.8 \%$ & $13.8 \%$ & $15.0 \%$ & $14.3 \%$ & $14.2 \%$ & $10.8 \%$ \\
\hline Physical inactivity ${ }^{\star \star}$ & $27.2 \%$ & $20.4 \%$ & $21.3 \%$ & $28.9 \%$ & $20.8 \%$ & $30.3 \%$ \\
\hline Alcohol use $e^{\star \star}$ & $2.1 \%$ & $3.4 \%$ & $5.0 \%$ & $2.6 \%$ & $3.6 \%$ & $7.3 \%$ \\
\hline Drug/medication use $\mathrm{e}^{\star \star}$ & $15.0 \%$ & $\mathrm{~N} / \mathrm{A}$ & $\mathrm{N} / \mathrm{A}$ & $12.3 \%$ & $10.8 \%$ & $10.5 \%$ \\
\hline Safety belt use ${ }^{\star \star}$ & $31.5 \%$ & $34.6 \%$ & $30.8 \%$ & $27.3 \%$ & $29.8 \%$ & $24.6 \%$ \\
\hline Absent due to illness ${ }^{\star *}$ & N/A & $14.8 \%$ & $14.4 \%$ & $5.9 \%$ & $7.8 \%$ & $7.2 \%$ \\
\hline Medical problems ${ }^{\star \star}$ & $7.4 \%$ & $10.9 \%$ & $13.3 \%$ & $5.5 \%$ & $6.7 \%$ & $12.0 \%$ \\
\hline High blood pressure ${ }^{\star \star}$ & $15.0 \%$ & $30.7 \%$ & $30.4 \%$ & $11.9 \%$ & $17.6 \%$ & $20.0 \%$ \\
\hline High cholesterol ${ }^{\star \star}$ & $14.2 \%$ & $11.7 \%$ & $12.4 \%$ & $13.2 \%$ & $18.8 \%$ & $5.7 \%$ \\
\hline Body Mass Index ${ }^{\star *}$ & $33.3 \%$ & $45.9 \%$ & $47.3 \%$ & $30.1 \%$ & $45.1 \%$ & $32.5 \%$ \\
\hline Personal life dissatisfaction ${ }^{\star *}$ & $19.5 \%$ & $18.0 \%$ & $18.9 \%$ & $22.6 \%$ & $16.3 \%$ & $24.7 \%$ \\
\hline Job dissatisfaction ${ }^{\star \star}$ & $18.1 \%$ & N/A & $\mathrm{N} / \mathrm{A}$ & $11.2 \%$ & $17.0 \%$ & $20.9 \%$ \\
\hline High stress ${ }^{\star *}$ & $29.7 \%$ & $23.8 \%$ & $26.5 \%$ & $36.2 \%$ & $26.1 \%$ & $26.9 \%$ \\
\hline Perception of health ${ }^{\star *}$ & $13.0 \%$ & $9.7 \%$ & $11.0 \%$ & $18.7 \%$ & $9.8 \%$ & $13.2 \%$ \\
\hline Health Age Index ${ }^{\star \star}$ & $2.2 \%$ & $8.2 \%$ & $9.2 \%$ & $3.4 \%$ & $6.9 \%$ & $4.4 \%$ \\
\hline \multicolumn{7}{|l|}{ Overall Risk Levell ${ }^{\star \star \star}$} \\
\hline Low risk & $59.8 \%$ & $58.3 \%$ & $55.8 \%$ & $59.0 \%$ & $58.6 \%$ & $57.5 \%$ \\
\hline Medium risk & $26.8 \%$ & $26.9 \%$ & $28.4 \%$ & $26.2 \%$ & $24.8 \%$ & $27.3 \%$ \\
\hline High risk & $13.4 \%$ & $14.8 \%$ & $15.8 \%$ & $14.8 \%$ & $16.5 \%$ & $15.3 \%$ \\
\hline
\end{tabular}

${ }^{*}$ Percent of HRA participants with risk.

${ }^{* \star} P<0.005, \chi^{2}$.

${ }^{* \star *} P<0.05, \chi^{2}$.

major diseases were higher than any of the risk level groups in each company. Cost ratios for those with disease ranged from 2.10 at Steelcase to 3.80 at Bank One; however, the differences were not significant. The medium-risk cost ratio ranged from a low of 1.10 at Steelcase to a high of 1.51 at Delphi but were not significant. The high-risk cost ratios ranged from a low of 1.13 at Bank One to a high of 2.09 at Delphi but were not significant. The percent excess cost of medium- and high-risk HRA participants, without major disease, compared with low risk participants, ranged from $8.3 \%$ at Bank One to $20.3 \%$ at Delphi. For those with disease compared with low-risk participants without disease, the percent excess cost ranged from $10.4 \%$ at Steelcase to $31.0 \%$ at Xerox. Com- bining medium and high-risk with disease, the percent excess cost ranged from $18.5 \%$ at Steelcase to $33.1 \%$ at Delphi compared with low risk without disease.

\section{Discussion}

The percent of total costs attributable to excess risks of HRA participants ranged from a low of $15.0 \%$ at Steelcase to a high of $30.8 \%$ at Del- 
TABLE 5

Ratio of Medical Expenses and Excess Costs for HRA Participants and Non-participants

\begin{tabular}{|c|c|c|c|c|c|c|c|c|c|c|c|c|}
\hline \multirow[b]{2}{*}{$\begin{array}{l}\text { Low-risk annual cost } \\
\text { ratio }^{*}(n=)\end{array}$} & \multicolumn{2}{|c|}{ Bank One } & \multicolumn{2}{|c|}{$\begin{array}{l}\text { UAW- } \\
\text { Delphi }\end{array}$} & \multicolumn{2}{|c|}{ UAW-GM } & \multicolumn{2}{|c|}{ Progressive } & \multicolumn{2}{|c|}{ Steelcase } & \multicolumn{2}{|c|}{ Xerox } \\
\hline & 1.00 & $(782)$ & 1.00 & (2613) & 1.00 & (6279) & 1.00 & (1159) & 1.00 & (628) & 1.00 & $(607)$ \\
\hline $\begin{array}{l}\text { High-risk annual cost } \\
\text { ratio* }(n=)\end{array}$ & $1.58^{\mathrm{a}}$ & (175) & $2.69^{a}$ & (661) & $2.33^{a}$ & (1778) & $2.03^{a}$ & (291) & $1.87^{\mathrm{a}}$ & (177) & $2.70^{a}$ & (161) \\
\hline $\begin{array}{l}\text { Non-participant annual } \\
\text { cost ratio* }(n=)\end{array}$ & $1.34^{\mathrm{ace}}$ & $(4727)$ & $1.65^{\mathrm{bc}}$ & (26046) & $1.41^{\mathrm{ac}}$ & $=(100227)$ & $1.33^{\mathrm{ac}}$ & $(6686)$ & $1.66^{\mathrm{bc}}$ & $(4164)$ & $1.29^{a c}$ & (2796) \\
\hline $\begin{array}{l}\text { Percent excess cost of } \\
\text { study population }\end{array}$ & $24.5 \%$ & & $38.3 \%$ & & $28.7 \%$ & & $23.8 \%$ & & $35.9 \%$ & & $24.4 \%$ & \\
\hline
\end{tabular}

${ }^{\mathrm{a}, \mathrm{b}}$ Means in a row with differing letters are statistically significant at $P<0.05$, GLM with Tukey-Kramer adjustment for multiple comparisons.

$\mathrm{c}, \mathrm{d}, \mathrm{e}$ Means in a row with differing letters are statistically significant at $P<0.01$, GLM with Tukey-Kramer adjustment for multiple comparisons.

${ }^{\star}$ Expressed as a ratio compared to low risk costs within a company.

\section{TABLE 6}

Ratio of Medical Expenses and Excess Costs for HRA Participants without Self-Reported Major Diseases* compared to HRA Participants with Self-Reported Major Diseases

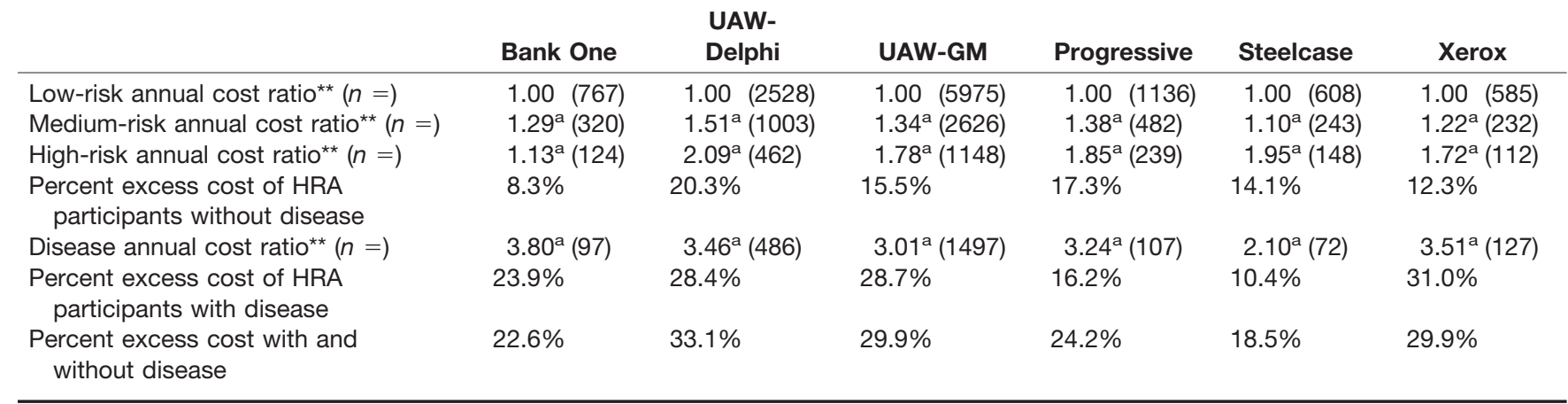

${ }^{*}$ Cancer, Diabetes, Heart Problems, Past Stroke, Chronic Bronchitis/Emphysema

a,b Means in a row with differing letters are statistically significant at $P<0.05$, GLM with Tukey-Kramer adjustment for multiple comparisons.

${ }^{\star *}$ Expressed as a ratio compared to low risk non-diseased costs within a company.

phi. This is similar to the results of others who showed that high-risk individuals had medical expenditures that were $10 \%$ to $21 \%$ higher $^{12}$ to twice as much ${ }^{25}$ as lower-risk individuals. Excess cost percentages were not statistically compared; however, there were no statistical differences between the companies for medium- and high-risk cost ratios; therefore, it would seem that the differences between the excess cost percentages would also tend to be not significant, even though the absolute numbers range from $15 \%$ to $30.8 \%$.

The medium range of percent of excess cost in this study was inter- esting considering the diversity and demographics of the companies. A manufacturing company was no more likely to have higher excess costs than a services company. This would lead one to believe that it is the risk level driving excess cost rather than the type of company or characteristics of their employees. When HRA nonparticipants are added to the calculation of percent of total costs attributable to excess risk, the range increases from a low of $23.8 \%$ at Progressive to a high of $38.3 \%$ at Delphi. These two examples show that higher or supposedly higher-risk individuals are costing these companies from a quarter to a third of their total medical claims. This would be in agreement with a study conducted at Texas A\&M University that showed that $43 \%$ of the costs of medical claims were associated with elevated risk. ${ }^{13}$ Similar results were seen at Procter and Gamble, where lifestyle related medical costs accounted for $35 \%$ of their 3-year medical costs. ${ }^{14} \mathrm{Nu}$ merous other studies have also shown the positive association between high-risk status and high medical costs. . $^{7,9,11}$

From a theoretical standpoint, some may argue that we have not shown the "true" excess cost caused by excess risk because we defined 
low risk as 0 to 2 risks instead of 0 risks. Although this is a valid argument, it is impractical to think that a health promotion program would ever be able to lower everyone to 0 risks. The potential savings would never be realized and may even negatively affect whether a health promotion program is considered successful. It is far more reasonable to think that a health promotion program may be able to lower a person from medium or high risk down to our definition of low risk, rather than 0 risks. Therefore, we believe that our estimation of potential cost savings would be more believable to a corporation without overselling the possible benefits of health promotion.

The excess cost of those with a self-reported major disease compared with low risk without major diseases varied from $10.4 \%$ at Steelcase to $31.0 \%$ at Xerox. Musich et $\mathrm{al}^{26}$ have shown previously an excess cost of $19.2 \%$ for the diseased GM population compared with the $28.7 \%$ in this study; however, their study calculated the percent excess cost only among those with disease and did not compare back to those without disease. Their study also included those older than 65 years of age. ${ }^{26}$ Using their numbers to calculate an excess cost for diseased individuals compared to low-risk nondiseased individuals gives a value of $36.4 \%$, which is similar to the $28.7 \%$ shown in this study.

As one would expect, major diseases are the dominant factors associated with high health costs within an employee population compared to other health risks. Those with disease had from 2.1 (Steelcase) to 3.8 (Bank One) times the cost of low risk people without disease. People with disease had higher costs than the high-risk people without disease. The cost of disease to a company is a function of the cost per individual and the number of individuals. For instance, Bank One has the highest disease cost ratio, but their prevalence rate (Table 4) is in the middle, so their overall disease excess cost percentage is moderate. Conversely, GM has a moderate disease cost ratio, yet their prevalence rate is the highest, so they end up having the second highest disease excess cost percentage. Steelcase has the best of both worlds by having the lowest disease cost ratio and the second lowest disease prevalence, resulting in the lowest disease excess cost percentage. The difference in disease excess cost percentage between the six companies is most likely the result of differences in demographics, with age being the biggest difference. Others have shown that medical costs increase as age increases $^{7}$ along with an increase in disease prevalence. $^{26,27}$

Although this study was not specifically designed to compare HRA participants and nonparticipants, it is obvious that participation is key to identifying risk levels. The average cost for HRA participants was lower than nonparticipants in all companies, except for Xerox. Other studies have shown that HRA participants had lower levels of risks ${ }^{28}$ and may $\operatorname{cost}$ less $^{29}$ than nonparticipants. Another study showed that high-risk individuals cost $44 \%$ to $92 \%$ more than HRA nonparticipants, which in turn were $11 \%$ to $17 \%$ higher than low-risk individuals. ${ }^{8}$ In this study HRA nonparticipants cost more on average than the known low-risk people. By increasing the HRA participation rate, companies would have a chance to identify those that may need help lowering their risk level or if they are low risk, keeping them that way.

Evaluating medical claims costs from different companies is an important step in finding ways to moderate or reduce health cost increases. It also further reinforces the concept of keeping low risk individuals in the low risk category while at the same time trying to reduce the risks of medium- and high-risk individuals. ${ }^{30}$

\section{Conclusion}

Medical cost patterns were relatively consistent across companies and appear to be independent of industry type, geographical location, company size, and demographics of the employees. As risk level increases, so do medical costs. Excess costs due to higher risk levels can account for a substantial portion of total medical costs. Reduction of risk level and keeping low-risk people at their current level could have the potential of reducing medical claims by a third. Depending on the size of the company, this reduction could easily run into the millions of dollars per year. ${ }^{31}$ These results also show the importance of having a program designed to lessen the impact of disease. Major disease appears to be the main factor driving medical costs, therefore the potential for cost savings or cost avoidance is high. Increasing HRA participation rate also appears to be an important consideration for companies as a method for identifying and helping those at risk.

\section{Limitations}

Criticism of using arithmetic means rather than a more sophisticated multifactorial analysis for medical claims cost has been leveled by others in the literature. ${ }^{13,32,33} \mathrm{Al}$ though this criticism may be valid because of the highly skewed nature of medical claims data, others have shown that the impact is not that great. ${ }^{34}$ By using a 2-year average we also reduced the skewedness of the data but did not eliminate it. With the use of means, our results may overestimate the possible savings. However, regardless of what statistical descriptor is used, the point still remains that over a period of 2 years the companies in this study paid more per year for higher risk individuals than they did for lower-risk individuals.

Some may question the use of risk factors that could also be outcomes, such as major diseases, illness days, and medication use. However, if those risks are ignored, an individual could have all three risk factors yet be classified as low risk. The effect of ignoring those risk factors would 
be an inflation of the baseline cost and an underestimation of the excess cost due to excess risk. While the merits of using each risk factor can be debated, the fact remains that companies have to pay for those costs.

The HRA participants from each company may be a biased group because their average cost ratio was lower than the non-participants (except for Xerox). If this were true, the only real impact would be overestimating the possible saving of the entire population. The percent excess costs of HRA participants should still be valid.

For the secondary analysis of selfreported major diseases, that is obviously dependent upon the HRA participant answering the question correctly to properly categorize the individual. A previous study has shown selfreported chronic conditions to be accurate in regards to medical records. ${ }^{35}$

\section{Acknowledgments}

The authors would like to thank the following for their assistance in data analysis: Shirley Musich, $\mathrm{PhD}$, Chin $\mathrm{Yu}$ Chen, $\mathrm{PhD}$, and Chi Fung Lu, MS.

\section{References}

1. US Census Bureau. Statistical Abstract of the United States 2001 (Table No. 692) Consumer Price Indexes (CPI-U) by Major Groups: 1980 to 2000. Available at: http://www.census.gov/prod/2002pubs/ 01statab/prices.pdf; accessed: July 1, 2004.

2. US Census Bureau. Statistical Abstract of the United States 2001 (Table No. 119) National Health Expenditures-Summary, 1960 to 1999, and Projections, 2000 to 2010. Available at: http://www.census. gov/prod/2002pubs/01statab/health.pdf; accessed: July 1, 2004.

3. Cowan C, McDonnell P, Levit K, Zezza M. Burden of health care costs: business, households, and governments, 19872000. Health Care Financing Rev. 2002; 23:131-159.

4. Berk M, Monheit A. The concentration of health care expenditures, revisited. Health Affairs. 2001;20:9-18.

5. US Department of Health and Human Services. Private Health Insurance Premiums in 1987; Policyholders Under Age
65. Rockville, MD: AHCPR publication 92-0061; 1992.

6. McCoy J, Iams H, Packard M, Shapiro J. Health of retired workers: survival status and medicare service use. Health Care Financing Rev. 1992;13:65-76.

7. Yen LT, Edington DW, Witting P. Corporate medical claim cost distributions and factors associated with high-cost status. J Occup Med. 1994;36:505-515.

8. Ozminkowski R, Dunn R, Goetzel R, et al. A return on investment evaluation of the Citibank, N.A., health management program. Am J Health Promot. 1999;14: 31-43.

9. Edington DW, Yen LT, Witting P. The financial impact of changes in personal health practices. J Occup Environ Med. 1997;39:1037-1046.

10. Yen LT, Edington DW, Witting P. Prediction of prospective medical claims and absenteeism costs for 1284 hourly workers from a manufacturing company. $J O C$ cup Med. 1992;34:428-435.

11. Yen LT, Edington DW, Witting, P. Associations between health risk appraisal scores and employee medical claims costs in a manufacturing company. Am J Prev Med. 1991;46-54.

12. Goetzel R, Anderson D, Whitmer R, et al. The relationship between modifiable health risks and health care expenditures. J Occup Environ Med. 1998;40:843854.

13. Kingery P, Ellsworth C, Corbett B, et al. High-cost analysis: a closer look at the case for work-site health promotion. J Occup Med. 1994;36:1341-1347.

14. Goetzel R, Jacobson B, Aldana S, et al. Health care costs of worksite health promotion participants and non-participants. J Occup Environ Med. 1998;40: 341-346.

15. Wasserman J, Whitmer R, Bazzarre T, et al. Gender-specific effects of modifiable health risk factors on coronary heart disease and related expenditures. J Occup Environ Med. 2000;42:1060-1069.

16. Edington D. Emerging research: a view from one research center. Am J Health Promot. 2001;15:341-349.

17. Bureau of Labor Statistics, U.S. Department of Labor, 2000 Consumer Price Index. Medical care costs. Available at: http://stats.bls.gov/cpi/cpid00av.pdf; accessed July 1, 2004.

18. SAS Institute Inc. SAS/STAT User's Guide.Version 6, 4th ed, Volumes 1\&2, Cary, NC: SAS Institute Inc.; 1989.

19. Musich S, Adams L, Hirschland D, et al. Benchmarking longitudinal health risk appraisal participation trends. AWHP's Worksite Health. 2001;8:37:43.

20. Musich S, Adams L, Edington D. Effec- tiveness of health promotion programs in moderating medical costs in the USA. Health Promotion Int. 2000;15:5-15.

21. Yen L, Edington M, Lu C, Edington D. Early survey evaluation of the United Auto Workers and General Motors Lifesteps health promotion program. Worksite Health. 1999;6:28-34.

22. Musich S, Napier D, Edington D. The association of health risks with workers' compensation costs. J Occup Environ Med. 2001;43:534-541.

23. Edington D, Yen L, Witting P. The financial impact of the changes in personal health practices. J Occup Environ Med. 1997;39:1037-1046.

24. Burton W, Hutchinson S, Helgeson L, Connor J. An evaluation of a worksite prenatal education program: Five-year experience. AWHP's Worksite Health. 2000;7:30-33.

25. Stein A, Karel T, Zuidema R. Carrots and sticks: Impact of an incentive/ disincentive employee flexible credit benefit plan on health status and medical costs. Am J Health Promot. 1999; 13:260-267.

26. Musich S, McDonald T, Hirschland D, et al. Excess healthcare costs associated with excess health risks in diseased and non-diseased health risk appraisal participants. Dis Manage Health Outcomes. 2002;10:251-258.

27. Hook M, Musich M, Edington D. Excess healthcare costs associated with excess health risks in the diseased and non-diseased. Healthcover. 2002;12: 19-25.

28. Lynch W, Gilfillan L, Jennett C, McGloin J. Health risks and health insurance claims costs. J Occup Med. 1993;35:2833.

29. Bly J, Jones R, Richardson J. Impact of worksite health promotion on health care costs and utilization: evaluation of Johnson \& Johnson's Live for Life program. JAMA. 1986;256:3235-3240.

30. Fries J, Harrington H, Edwards R, et al. Randomized controlled trial of cost reductions from a health education program: the California Public Employees' Retirement System (PERS) Study. Am J Health Promot. 1994;8:216-223.

31. Ozminkowski R, Goetzel R, Smith M, et al. The impact of the Citibank, NA, health management program on changes in employee health risks over time. $J O_{c}$ cup Environ Med. 2000;42:502-511.

32. Goetzel R, Dunn R, Ozminkowski R, et al. Differences between descriptive and multivariate estimates of the impact of Chevron Corporation's health quest program on medical expenditures. J Occup Environ Med. 1998;40:538-545. 
33. Pelletier K. A review and analysis of the clinical and cost-effectiveness studies of comprehensive health promotion and disease management programs at the worksite: 1995-1998 update (IV).
Am J Health Promot. 1999;13:333-345.

34. Diehr P, Yanez D, Ash A, et al. Methods for analyzing health care utilization and costs. Anпи Rev Public Health. 1999;20: $125-144$.
35. Martin L, Leff $\mathrm{M}$, Calonge $\mathrm{N}$, et al. Validation of self-reported chronic conditions and health services in a managed care population. Am J Prev Med. 2000; $18: 215-218$. 